ISSN: 2224-0616

Int. J . Agril. Res. Innov. \& Tech. 4 (2): 46-52, December, 2014 Available online at http://www.ijarit.webs.com

\title{
KNOWLEDGE AND PERCEPTION OF EXTENSION WORKERS TOWARDS ICT UTILIZATION IN AGRICULTURAL EXTENSION SERVICE DELIVERY IN GAZIPUR DISTRICT OF BANGLADESH
}

\author{
F.A. Prodhan" ${ }^{*}$ and M.S.I. Afrad ${ }^{2}$
}

Received 3 July 2014, Revised 10 November 2014, Accepted 22 December 2014, Published online 31 December 2014

\begin{abstract}
The primary purpose of the study was to assess the extent of knowledge and perception of extension workers towards ICT utilization and to determine the relationship between the selected characteristics of the respondents and knowledge and perception of extension workers towards ICT utilization in extension service delivery. The study was conducted in Gazipur district and comprised proportionate random sample of 90 extension workers from five upazila of Gazipur district. A pre-tested interview schedule was used to collect data from the respondents. To measure the knowledge on ICT utilization 35 statements were selected regarding 7 ICT with five possible answer of each tools and a score of one was given to the right answer and zero to the wrong answer alternatively to measure the perception of the respondents rated each of 10 statements ICT utilization in agriculture on a 5-point Likert type scale and the total of these ratings formed perception index. The result of the study showed that out of seven ICT tools the knowledge of extension workers was highest in case of MS Word this was followed by internet/ web service and the lowest knowledge was found in case of Geographical Information System. It is observed that an overwhelming majority (88.9\%) of agricultural extension workers in the study area had low to medium knowledge towards ICT utilization. Findings reveal that the respondents had top most perception on the ICT utilization in respect of 'Extension work can be greatly enhanced by ICT' followed by on 'The benefits of ICT use outweigh the financial burden involved'. The result also indicated that more than fourth-fifth $(84.4 \%)$ of the respondents had medium to high perception towards ICT utilization. There were significant relationship between service experience and use of the information sources of the respondents with their knowledge towards ICT utilization conversely innovativeness, cosmopoliteness and job satisfaction of the respondents showed positive significant relationship with their perception towards ICT utilization.
\end{abstract}

Keywords: Knowledge, Perception, ICT and Extension Workers

${ }^{1}$ Lecturer, Department of Agricultural Extension and Rural Development, Bangabandhu Sheikh Mujibur Rahman agricultural University, Gazipur-1706, Bangladesh

${ }^{2}$ Professor, Department of Agricultural Extension and Rural Development, Bangabandhu Sheikh Mujibur Rahman agricultural University, Gazipur-1706, Bangladesh

*Corresponding author's email: foyez_bsmrau @yahoo.com (F.A. Prodhan)

\section{Introduction}

Agriculture is a major economic activity in Bangladesh. It currently employs about 50 per cent of the country's labor force and contributes about 20 per cent of country's gross domestic product (GDP) (World Bank, 2008). In Bangladesh, about 70 per cent of poor people live in the rural areas, and these poor people are concentrated in the agricultural sector (Raihan, 2012). The role of agricultural extension service has traditionally been to provide the important link between agricultural research and farming communities, especially for technology transfer in support of agricultural and rural development (FAO, 2004). Agricultural extension service over the years has been working via different approaches, methodologies and program to ensure farmers adoption of improved technologies with little success (Aker, 2010). Agricultural extension program can provide much-needed help in the form of practical fieldadvice, innovations from scientists and practitioners, and sound commodity-marketing principles. Yet the enormous demand for smallholder training can never be met through conventional extension methods. Arokoyo (2005) reported that a strong agricultural extension linkage complimented by flawless information flow enhanced by the effective use of information and communication technologies (ICT) would significantly boost agricultural production and improve rural livelihoods in developing countries. Agriculture is one of the vital sectors in which ICT can be used reasonably in transferring the modern agricultural technologies to the farmers. ICT has many potential applications in agricultural extension most especially in accessing required information and knowledge (McNamara, 2009). Information and 
communication technology in agriculture includes internet, radio/community radio, television, wireless communication tools, cell phone, audio visuals, digital camera, Geographic Information System (GIS), Global Positioning System (GPS) and other technologies which direct the agricultural activities towards precision agriculture (Mirzaei, 2003). ICT can bring new information services to rural areas where farmers, users, will have much greater control. It follows from the foregoing that ICT are information transmission technology built on the potential of electronic communication devices such as computers and telecommunication equipment, for connecting and accessing various ends in the information pathway (Aboh, 2008). ICT as an extension tool could enhance the flow of information in the application of agricultural extension services. Agricultural extension, which depends largely on information exchange between and among farmers, has been identified as one area in which ICT can have a particularly significant impact (Ballantyne and Bokre, 2003). The introduction of various relevant ICTs in agricultural information dissemination could help farmers' access market information, land resources and services, management of pest and diseases, rural development program and help in broadening the orientation of farmers in production activities thereby causing a major turnaround in the agricultural sector as it is doing in many other sectors (Meera et al., 2004). If extension agents are crucial to agricultural and rural development and use of various ICTs promises boost for agricultural and rural development, then a study on the knowledge and perception of extension agents on ICT utilization in extension service delivery is important. Considering this in view, the present study was undertaken with the following objectives:

1) To identify the socio-demographic characteristics of the extension workers;

2) To assess the extent of knowledge and perception of extension workers towards ICT utilization in extension service delivery; and

3) To determine the relationship between the selected characteristics of the respondents and knowledge and perception of extension workers towards ICT utilization in extension service delivery.

\section{Methodology}

The study was conducted in Gazipur district, which consist of five upazilas viz. Kapasia, Sreepur, Kaliakoir, Kaligonj and Gazipur Sadar upazila. The Sub Assistant Agriculture Officers (SAAOs) of the Gazipur district were the target population of this study. The total target population in Kapasia, Sreepur, Kaliakoir, Kaligonj and Gazipur Sadar upazilas, of Gazipur district were 214, out of this population, a number of 90 (42\%) SAAOs were selected as the sample of the study following the proportionate random sampling. A pre-tested interview schedule was used to collect data from the respondents. Selected characteristics of the respondents' viz. age, service experience, training exposure, job satisfaction, innovativeness, cosmopoliteness, use of information sources and aspiration were considered as independent variables of the study. To measure the knowledge on ICT utilization 35 statements were selected regarding 7 ICT tools. These were presented to the respondents with 5 possible answers for each ICT tool. A score of one was given to the right answer and zero to the wrong answer. The possible obtainable scores ranged between 35 and 0 respectively. Based on the total score obtained by the respondents of each ICT tool Knowledge Index was worked out by using the following formula.

$$
\text { Knowledge Index }(\mathrm{KI})=\frac{\text { Scores obtained }}{\text { Obtainable scores }} \text { x } 100
$$

To measure perception of the respondents towards ICT utilization a 5-point Likert type scale ranging from 1 as 'strongly disagree' to 5 as 'strongly agree' used for the measurement. The respondents were asked to rate 10 statements based upon a five-point Likert type scale towards ICT utilization in agriculture. A perception score of a respondent was obtained by summing up the weights for his 10 statements regarding ICT utilization in agricultural extension. The perception score of a respondent could range from 10 to 50, while 10 indicating low perception and 50 indicating highest level of perception. In order to measure the extent of perception on the statement towards ICT utilization Perception Index (PI) was used as developed by Biswas (2004).

$$
\begin{aligned}
& \text { Perception Index }(P I)=\frac{f_{1} X_{1}+f_{2} X_{2}+\ldots \ldots+f_{n} X n}{N} \times 100 \\
& =x 100-\sum_{i=0}^{n} f_{n} X_{n}
\end{aligned}
$$

Where,

$\mathrm{X}_{\mathrm{i}}=$ scale value at the $\mathrm{i}^{\text {th }}$ priority of the statement

$\mathrm{f}_{\mathrm{i}}=$ Frequency of responses on that statement

$\mathrm{n}=$ number of statements in the parameter

$\mathrm{N}=$ number of respondents

$\mathrm{i}=1,2,3, \ldots . \mathrm{n}$ 


\section{Results and Discussion}

\section{Personal characteristics of the respondents}

Characteristics profile of the extension workers were determined and presented in Table 1. The findings indicate that most of the respondents were middle aged (56.7\%) followed by short-term service experience (62.2\%). It is also found that majority of them had low training experience (47.8\%) while two-fifth (40\%) had no training, high innovativeness (55.6\%), medium cosmopoliteness (70\%) and medium job satisfaction (56.7\%). It was also indicate that most of them used medium information sources (64.4\%) and had medium aspiration (45.6\%).

Table 1. Distribution of the respondent according to their socio-economic characteristics

\begin{tabular}{|c|c|c|c|c|c|c|}
\hline Character & $\begin{array}{l}\text { Measuring } \\
\text { unit }\end{array}$ & Categories & $\begin{array}{c}\text { No. of } \\
\text { respondents }\end{array}$ & Per cent & Mean & $\mathrm{SD}$ \\
\hline & \multirow{3}{*}{ Actual year } & Young aged (up to 35) & 28 & 31.1 & \multirow{3}{*}{37.04} & \multirow{3}{*}{6.68} \\
\hline \multirow[t]{2}{*}{ Age } & & Middle aged (36-45) & 51 & 56.7 & & \\
\hline & & Old $(>45)$ & 11 & 12.2 & & \\
\hline \multirow{4}{*}{ Service experience } & \multirow{4}{*}{$\begin{array}{l}\text { Year of } \\
\text { service }\end{array}$} & Short term (up to 10 years) & 15 & 62.2 & \multirow{4}{*}{10.24} & \multirow{4}{*}{6.17} \\
\hline & & Medium term (11- 20 years) & 56 & 27.8 & & \\
\hline & & Long term ( $>20$ years) & 25 & 10 & & \\
\hline & & No training & 36 & 40 & & \\
\hline \multirow{3}{*}{ Training exposure } & \multirow[t]{3}{*}{ Number } & Low training( 1 to 3 ) & 43 & 47.8 & \multirow{3}{*}{1.41} & \multirow[t]{3}{*}{-} \\
\hline & & Medium training (4-5) & 11 & 12.2 & & \\
\hline & & Low (up to18) & 19 & 21.10 & & \\
\hline \multirow[t]{3}{*}{ Innovativeness } & \multirow[t]{3}{*}{ Scores } & Medium (19-30) & 21 & 23.30 & \multirow[t]{3}{*}{24.49} & \multirow[t]{3}{*}{6.97} \\
\hline & & High $(>30)$ & 50 & 55.6 & & \\
\hline & & Low (up to 15) & 16 & 17.8 & & \\
\hline \multirow[t]{3}{*}{ Cosmopoliteness } & \multirow[t]{3}{*}{ Scores } & Medium (16 to 25$)$ & 63 & 70 & \multirow[t]{3}{*}{19.67} & \multirow[t]{3}{*}{4.37} \\
\hline & & High ( >25) & 11 & 12.2 & & \\
\hline & & Low (up to 22) & 23 & 25.5 & & \\
\hline \multirow[t]{2}{*}{ J ob satisfaction } & \multirow[t]{2}{*}{ Scores } & Medium (23to 34) & 51 & 56.7 & \multirow[t]{2}{*}{28.44} & \multirow[t]{2}{*}{6.66} \\
\hline & & High (>34) & 16 & 17.8 & & \\
\hline \multirow{4}{*}{$\begin{array}{l}\text { Use of information } \\
\text { sources }\end{array}$} & \multirow{4}{*}{ Score } & Low ( up to 18) & 18 & 20 & \multirow{4}{*}{23.03} & \multirow{4}{*}{5.12} \\
\hline & & Medium (19-28) & 58 & 64.4 & & \\
\hline & & Hiqh $(>18)$ & 14 & 15.6 & & \\
\hline & & Low ( up to 12 ) & 28 & 31.1 & & \\
\hline \multirow{2}{*}{ Aspiration } & \multirow{2}{*}{ Score } & Medium (13-16) & 41 & 45.6 & \multirow{2}{*}{14.12} & \multirow{2}{*}{2.80} \\
\hline & & High $(>16)$ & 21 & 23.3 & & \\
\hline
\end{tabular}

\section{Knowledge on ICT utilization}

The Knowledge of the agricultural extension workers towards ICT utilization were conceptualized as consisting of seven ICT tools namely i)Internet/ Web services, ii) MS Word, iii) MS Excel, iv) MS Power point, v) Analytical packages SPSS, vi) Geographical Information System (GIS) and vii) Web based searched engine. For each ICT tools of knowledge the respondents' actions were arbitrarily judged from 0 to 5 continuums. The salient features of different ICT tools have been presented in Table 2 and Table 3.

Table 2. Rank order of the ICT tools regarding knowledge of the respondents based on theirKnowledge Index (KI) and mean score

\begin{tabular}{llccc}
\hline Sl. No. & ICT tools & Knowledge Index(KI) & Mean & Rank order \\
\hline 1. & Internet/Web service & 78 & 3.89 & $2^{\text {nd }}$ \\
2. & MS Word & 80 & 3.99 & $1^{\text {st }}$ \\
3. & MS Excel & 56 & 2.78 & $5^{\text {th }}$ \\
4. & Microsoft Power Point & 59 & 2.94 & $4^{\text {th }}$ \\
5. & Analytical package SPSS & 53 & 2.63 & $6^{\text {th }}$ \\
6. & Geographical Information System (GIS) & 51 & 2.54 & $7^{\text {th }}$ \\
7. & Web based search engine & 62 & 3.10 & $3^{\text {rd }}$ \\
\hline
\end{tabular}

The knowledge of extension workers was highest in case of MS Word tool $(\mathrm{KI}=80)$ with mean score 3.89 (Table 2) because more than fourth-fifth (84.4\%) of the respondents know that bold, italic, underline, alignment, spelling and grammar can be checked through it and 83.3 per cent of the respondents be familiar with that it is word processor (Table 3). This was followed by Internet/Web service $(\mathrm{KI}=78)$ with mean score 3.89 (Table 2) as 88.9 percent respondents be aware of that it helps to get information, data and images almost instantaneously (Table 3 ) this might be the fact that of above findings. In case of web based search engine the knowledge Index 
(KI) of the respondents was 62 with mean score the information on the internet and for this 3.10 ranked third. The reason behind this 70 browser software like 'Internet Explorer' or percent of the respondents know about that it Mozilla Firefox is required on computer (Table 3). includes 'Google', Yahoo', or 'Alta Vista' to find

Table 3. Distribution of the respondents based on their knowledge on seven ICT tools

\begin{tabular}{|c|c|c|c|}
\hline $\begin{array}{l}\text { ICT } \\
\text { tools }\end{array}$ & Statements & Yes & No \\
\hline \multirow{5}{*}{ 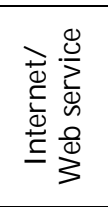 } & Internet is a worldwide network of networks. & $76(84.4)$ & $14(15.6)$ \\
\hline & It is a global network connecting millions of computers. & $77(85.6)$ & $13(14.4)$ \\
\hline & iii) It makes contact with people by chat facility. & $58(64.4)$ & $32(35.6)$ \\
\hline & iv) It helps to get information, data and images almost instantaneously & 80 (88.9) & $10(11.1)$ \\
\hline & $\begin{array}{l}\text { Unlike online services, which are centrally controlled, the internet is } \\
\text { decentralized by design. }\end{array}$ & $50(55.6)$ & $40(44.4)$ \\
\hline \multirow{5}{*}{$\sum_{\substack{\infty \\
0}}^{\sum_{1}^{\infty}}$} & It is word processor & 75 (83.3) & $15(16.7)$ \\
\hline & Microsoft Word is a powerful tool to create professional looking & $72(80)$ & $18(20)$ \\
\hline & $\begin{array}{l}\text { iii) Bold, italic, underline, alignment, spelling and grammar can be } \\
\text { checked through it. }\end{array}$ & $76(84.4)$ & $14(15.6)$ \\
\hline & iv) Word formatting is done through this software. & $69(76.7)$ & $21(23.3)$ \\
\hline & It creates a new, blank file bases on the defau & $67(74.4)$ & $23(25.6)$ \\
\hline \multirow{5}{*}{ 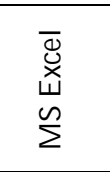 } & Excel is a data processor & $48(53.3)$ & $42(46.7)$ \\
\hline & Microsoft Excel also serves as database mana & $56(62.2)$ & 34 (37.8) \\
\hline & iii) It stores data in the forms of columns and ror & $60(66.7)$ & 30 (33.3) \\
\hline & iv) In excel there are 256 columns and 65536 rows. & 39 (43.3) & $51(56.7)$ \\
\hline & v) Excel helps in entering values, text, formulas etc. & $47(52.2)$ & $43(47.8)$ \\
\hline \multirow{5}{*}{ 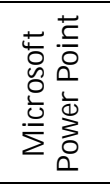 } & It is presentation program developed by Microsoft. & $68(75.6)$ & $22(24.4)$ \\
\hline & ii) It consists of a number of individual pages or slides. & $61(67.8)$ & $29(37.2)$ \\
\hline & ality slide show can be m & $46(51.11)$ & $44(48.9)$ \\
\hline & iv) It helps in & $59(65.5)$ & $31(34.4)$ \\
\hline & v) Animation can be done through this. & $33(36.7)$ & $57(63.3)$ \\
\hline \multirow{5}{*}{ 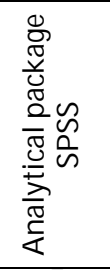 } & \multirow{2}{*}{$\begin{array}{l}\text { It is among the widely used programs for statistical analysis. } \\
\text { It is used for market, health government, education and other research } \\
\text { purpose. }\end{array}$} & $53(58.9)$ & $37(411)$ \\
\hline & & $41(45.6)$ & $49(54.4)$ \\
\hline & $\begin{array}{l}\text { ii) It manages millions of rows effortlessly, so you will never again have to } \\
\text { break up your data and analyze it piecemeal }\end{array}$ & $47(52.2)$ & $43(47.8)$ \\
\hline & \multirow{2}{*}{$\begin{array}{l}\text { iv) This eliminates duplicate records and jumbled cases } \\
\text { v) SPSS has measures of significance that allow confident, actionable }\end{array}$} & $33(36.7)$ & $57(63.3)$ \\
\hline & & $45(50)$ & $45(50)$ \\
\hline \multirow{5}{*}{ 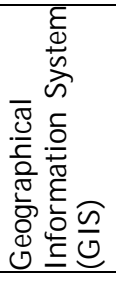 } & \multirow{2}{*}{$\begin{array}{l}\text { GISis for analysis and management of spatial data and mapping. } \\
\text { i) It helps to get information like populations, literacy level, density of } \\
\text { roads, land etc. }\end{array}$} & $49(54.4)$ & $41(45.6)$ \\
\hline & & $47(52.2)$ & $43(47.8)$ \\
\hline & & $40(44.4)$ & $50(55.6)$ \\
\hline & $\begin{array}{l}\text { iv) It also helps in comparing spatial data to support some analytical } \\
\text { process. }\end{array}$ & $47(52.2)$ & $43(47.8)$ \\
\hline & $\begin{array}{l}\text { v) Use of GIS in socioeconomic research, characterization of production } \\
\text { system according to adoption of improved technologies }\end{array}$ & $46(51.1)$ & $44(48.9)$ \\
\hline \multirow{5}{*}{ 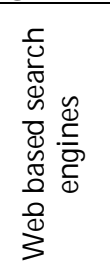 } & $\begin{array}{l}\text { i) A Web search engine is a tool designed to search for information on } \\
\text { the World Wide Web }\end{array}$ & $49(54.4)$ & $41(45.6)$ \\
\hline & ii) It helps to search items in the search statement & $62(68.9)$ & $28(31.1)$ \\
\hline & $\begin{array}{l}\text { iii) It includes 'Google', 'Yahoo', or 'Alta Vista' to find the information on } \\
\text { the internet }\end{array}$ & $63(70)$ & $27(30)$ \\
\hline & $\begin{array}{l}\text { iv) For this browser software like 'Internet Explorer' or Mozilla Firefox is } \\
\text { required on computer }\end{array}$ & $63(70)$ & $27(30)$ \\
\hline & v) Information consists of web pages, images, and other types of files & 48 (53.3) & $42(46.7)$ \\
\hline
\end{tabular}

Note: 1) Figures in the parenthesis indicate percentage 2) Multiple responses are possible

The extension workers had moderate knowledge number of individual pages or slides while in case in case of Microsoft Power Point ( $\mathrm{KI}=59)$ and MS of MS Excel 66.7 per cent respondents are slightly Excel $(\mathrm{KI}=56)$ with mean score 2.94 and 2.78, friendly with that MS Excel stores data in the respectively (Table 2). In case of Microsoft Power forms of columns and rows (Table 3). The point three-fourth (75.6\%) of the respondents be extension workers had very poor knowledge in acquainted with that Microsoft Power Point is case of Analytical package SPSS (KI=51) and presentation program developed by Microsoft Geographical Information System (GIS) (KI=51) and 67.8 per cent of respondents have knowledge with mean score 2.63 and 2.54, respectively of that Power Point presentations consist of a (Table 2). This is because only 58.9 per cent 
respondents know that SPSS is among the widely used programs for statistical analysis and 54.4 per cent respondents be aware of that GIS is for analysis and management of spatial data and mapping.

Best on total score of the respondents regarding seven ICT tools the overall knowledge score of respondents were classified into three categories namely low (less than mean - S.D.), medium (between mean \pm S.D.) and high (more than mean + S.D.) has been presented in Fig. 1. Observed knowledge scores of the respondents ranged from 15 to 32 against possible range from 0 to 35 with mean and standard deviation were 21.88 and 3.04, respectively.

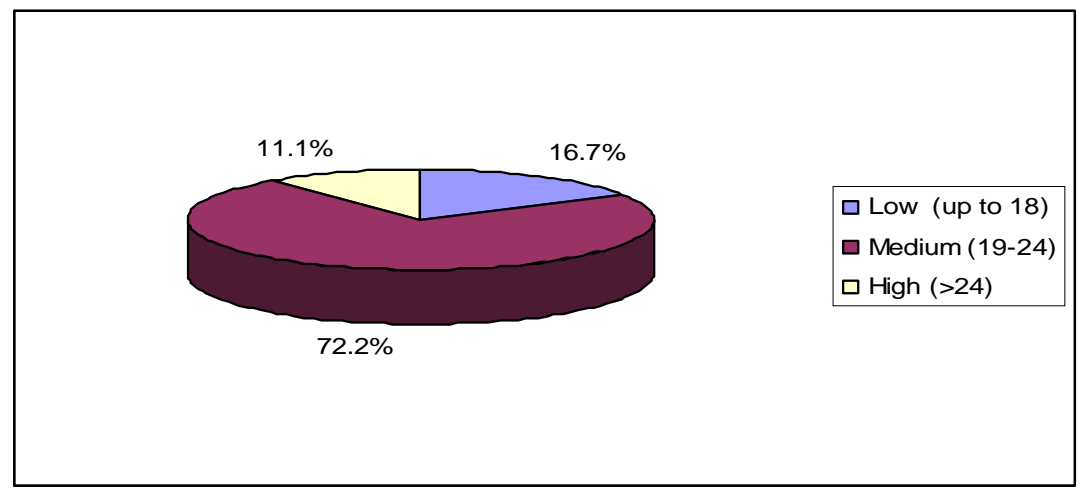

Fig. 1. Distribution of the respondents based on their overall knowledge score towards ICT utilization

Data presented in Figure 1 demonstrate that 16.7 per cent of the respondents had low knowledge while about three-fourth (72.2\%) of the respondents had medium knowledge on ICT and only 11.1 had high knowledge towards ICT utilization. However, it is observed that an overwhelming majority (88.9\%) of agricultural extension workers in the study area had low to medium knowledge. Therefore, one may apprehend that due to moderate and poor knowledge on most of the ICT tools except MS
Word and Internet/Web service most of the respondents of the study area might have low to medium knowledge.

\section{Perception towards ICT utilization}

A rank order of 10 statements regarding ICT utilization according to their Perception Index (PI) has been presented in Table 4 for a clear understanding of the comparative perception of the respondents on the statements.

Table 4. Rank order of the statement regarding ICT utilization according to their perception index

\begin{tabular}{|c|c|c|c|c|c|c|c|c|}
\hline Sl\# & Perceptional Statements & SA & A & UD & DA & SDA & PI & Ranking \\
\hline 1. & $\begin{array}{l}\text { Knowledge of ICT use has a great significance } \\
\text { in agricultural development }\end{array}$ & 31 & 25 & 23 & 8 & 3 & 381 & $3^{\text {rd }}$ \\
\hline 2. & $\begin{array}{l}\text { It's a waste of time bringing ICT into } \\
\text { agriculture }\end{array}$ & 28 & 28 & 18 & 9 & 7 & 368 & $5^{\text {th }}$ \\
\hline 3. & ICT use influences rate of adoption & 29 & 29 & 12 & 18 & 2 & 372 & $4^{\text {th }}$ \\
\hline 4. & $\begin{array}{l}\text { Extension work can be greatly enhanced by } \\
\text { ICT }\end{array}$ & 36 & 24 & 19 & 9 & 2 & 392 & $1^{\text {st }}$ \\
\hline 5. & $\begin{array}{l}\text { The benefits of ICT use outweigh the financial } \\
\text { burden involved }\end{array}$ & 28 & 32 & 22 & 6 & 2 & 387 & $2^{\text {nd }}$ \\
\hline 6. & $\begin{array}{l}\text { ICT removes a lot of cost, barriers and saves } \\
\text { timein transferring technology }\end{array}$ & 18 & 27 & 20 & 19 & 6 & 336 & $7^{\text {th }}$ \\
\hline 7. & $\begin{array}{l}\text { Infrastructural facilities to support ICT use is } \\
\text { not available }\end{array}$ & 13 & 19 & 40 & 17 & 1 & 329 & $9^{\text {th }}$ \\
\hline 8. & $\begin{array}{l}\text { ICT use is good but not necessary in extension } \\
\text { service delivery }\end{array}$ & 27 & 23 & 16 & 23 & 1 & 358 & $6^{\text {th }}$ \\
\hline 9. & $\begin{array}{l}\text { The financial burden of using ICT is } \\
\text { unbearable }\end{array}$ & 6 & 25 & 31 & 27 & 1 & 309 & $10^{\text {th }}$ \\
\hline 10. & ICT are too complicated and hard to use & 11 & 32 & 23 & 22 & 2 & 331 & $8^{\text {th }}$ \\
\hline
\end{tabular}


Data contained in Table 4 indicate that the respondents had top most perception on the ICT utilization in respect of 'extension work can be greatly enhanced by ICT' was the highest (PI=392) followed by on the benefits of ICT use outweigh the financial burden involved' was the second highest (PI=387) and knowledge of ICT use has a great significance in agricultural development' (PI= 381) was third. Perception was lowest (PI=309) in respect of The financial burden of using ICT is unbearable'. The respondents showed 'infrastructural facilities to support ICT use are not available' was the second lowest (226). Perception Indices (PI) towards ICT utilization of 10 statements were between 392 to
309 maximum possible perception indexs (PI) is 450 and that of six statements between 350 and 400. However, none of the statements has between 401 and 450; these facts indicate that perception of the respondents was considerably moderate in comparison to the maximum possible level on all the statements.

Extension workers' perception score was further analyzed and the summary presented in Table 5. Data contained in Table 5 indicate that the highest proportion (64.4\%) of the respondents fell in medium perception category compared to 20 percent in high and 15.6 per cent in low perception category.

Table 5. Distribution of respondents according to their extent of perception

\begin{tabular}{lcccc}
\hline Category & \multicolumn{2}{c}{ Respondents } & Mean & SD \\
\cline { 2 - 3 } & Frequency & Per cent & \\
\hline Low (up to 31) & 14 & 15.6 & & \\
Medium (32-39) & 58 & 64.4 & 35.62 & 4.26 \\
High (>39) & 18 & 20.0 & & \\
Total & 90 & 100.0 & & \\
\hline
\end{tabular}

The findings reveal that only 15.6 per cent of the extension workers in the study area had low perception towards ICT utilization. More than fourth-fifth (84.4\%) of the respondents had medium to high perception towards ICT utilization because most of the respondents be aware of that extension work can be greatly enhanced by ICT and Knowledge of ICT use has a great significance in agricultural development. This may have positive impact in transferring the modern agricultural technologies to the farmers for sustainable agricultural production.

Relationship between the selected characteristics of the respondents and extent of knowledge and perception towards ICT utilization

The variables studied were subjected to correlation analysis using Pearson product moment correlation to find out the relation between the independent variables and dependent variables (knowledge and perception on various ICTs). Results in Table 5 reveals that there was no significant relationship between the age, aspiration, innovativeness, cosmopoliteness, training exposure and job satisfaction towards ICT utilization but service experience and use of the information sources of the respondents showed positive and significant relationship with their knowledge towards ICT utilization. This implies that more service experience and more use of information sources of the respondents leads to a tendency towards more knowledge towards ICT utilization in agricultural extension service delivery i.e., extension workers with medium and high service experience and use of information sources had more knowledge towards ICT utilization. This might be due to high service experience and large number use of source of information help one able to become more knowledgeable and more innovative and also keep up to date with the latest technology.

Table 6. Relationship between the selected characteristics of the respondents and their knowledge and perception towards ICT utilization

\begin{tabular}{lcc}
\hline Characteristics of the & Knowledge (r value) & Perception (r value) \\
extension workers & $0.173^{(\mathrm{NS})}$ & $0.143^{(\mathrm{NS})}$ \\
\hline Age & $0.261^{*}$ & $0.193^{(\mathrm{NS})}$ \\
Service experience & $-0.134^{\text {(NS) }}$ & $0.123^{(\mathrm{NS})}$ \\
Training exposure & $0.151^{(\mathrm{NS})}$ & $0.578^{* *}$ \\
Innovativeness & $-0.028^{(\mathrm{NS})}$ & $0.236^{*}$ \\
Cosmopoliteness & $0.060^{\text {(NS) }}$ & $0.236^{*}$ \\
Job satisfaction & $0.273^{*}$ & $.0058^{(\mathrm{NS})}$ \\
Use of information sources & $0.189^{\text {(NS) }}$ & $0.197^{(\mathrm{NS})}$ \\
Aspiration & &
\end{tabular}

* Significant at 0.05 level of probability, ** Significant at 0.01 level of probability, NS = Non significant 
On the other hand, out of eight selected characteristics of the respondents' innovativeness, cosmopoliteness and job satisfaction showed positive significant relationship with their perception towards ICT utilization indicating that respondents having higher innovativeness, cosmopoliteness and job satisfaction more likely to have more perception towards ICT utilization in agricultural extension service delivery. Because through cosmopoliteness quality, an individual becomes aware of the recent information and innovativeness of an individual helps to adopt new ideas and technology. High job satisfaction creates positive response toward various facets of one's job, which make an individual more competitive to perform his duty.

\section{Conclusion}

Agricultural development can be accelerated and livelihoods can be supported by ICT in so many ways. The dramatic changes that have taken place in the last decade in ICT have touched almost every field of human activity, and agriculture is not an exception. ICT has tremendous potential to revolutionize the way information, knowledge and new technology is managed, developed and delivered to farmers through ICT utilization in agriculture. Findings of the study reveals that knowledge of extension workers among the seven ICT tools was highest in case of MS Word this was followed by Internet/ Web service and web based search engine. The extension workers had moderate knowledge in case of Microsoft Power Point and of MS Excel while the extension workers showed very poor knowledge in case of Analytical package SPSS and Geographical Information System (GIS). It was also found that an overwhelming majority (88.9\%) of agricultural extension workers in the study area had over all low to medium knowledge towards ICT utilization. Among the ten statements regarding extension workers perception towards ICT utilization, 'extension work can be greatly enhanced by ICT' was the highest followed by on the benefits of ICT use outweigh the financial burden involved' was the second highest score. Furthermore it was observed that more than fourth-fifth (84.4\%) of the respondents had medium to high perception towards ICT utilization because most of the respondents be aware of that extension work can be greatly enhanced by ICT and knowledge of ICT use has a great significance in agricultural development. Service experience and use of the information sources of the respondents showed positive and significant relationship with their knowledge towards ICT utilization conversely innovativeness, cosmopoliteness and job satisfaction showed positive significant relationship with their perception towards ICT utilization. The study recommends that adequate information on various relevant ICT suitable for extension service delivery should be given to extension agents so that they can improve their knowledge and on it help them to develop more positive perception that will enhance the future use of these ICT in extension service delivery.

\section{References}

Aboh, L.C. 2008. Assessment of the frequency of ict tools usage by agricultural extension agents in Imo State, Nigeria. J . Agric. Social Res. 8: 21-30.

Aker, J.C. 2010. Dial 'A' for Agriculture: using information and communication technologies for agricultural extension in developing countries. Tuft University, Economics Department and Fletcher School, Medford MA02155. p. 37.

Arokoyo, T. 2005. ICTs application in agricultural extension service delivery. In: S.F. Adedoyin (Ed.), Agricultural Extension in Nigeria. llorin, Nigeria: Agricultural Extension Society of Nigeria. pp. 245-251.

Ballantyne, P. and Bokre, D. 2003. ICTs: transforming agricultural extension? Report of an iNARSe-discussion, Retrieved October 15, 2007 from: http:// www.livelihoods.org/info/ docs/inars Supersummary.pdf

Biswās, S. 2004. Women's empowerment and demographic changes. Bangladesh Academy for Rural Development, Kotbari, Comilla. pp. 147-152.

FAO. 2004. Institute building to strengthen agricultural extension. 27th FAO Regional Conference for Asia and the pacific Beijing, china, May, 17th - 21st, 2004. pp. 22-28.

McNamara, K. 2009. Improving agricultural productivity and markets: The role of information and communication technologies. agriculture and rural development notes, Issue 47, April, The World Bank, Washington DC. p. 4.

Meera, S.N., J hamtani, A. and Rao, D.U.M. 2004. Information and communication technologies in agricultural development: A comparative analysis of three projects from india. Agricultural Research and Extension Network. New Delhi, India. p. 135.

Mirzaei, A. 2003. Country Report of Islamic Republic of Iran. The study meeting on application of information technology for effective agricultural extension. New Delhi, India p. 13.

Raihan, S. 2012. Economic reforms and agriculture in Bangladesh: Assessment of impacts using economy-wide simulation models / Selimraihan; International Labour Organization; ILO Country Office for Bangladesh. Dhaka: ILO, 2012. Available at: http:/ / www.ilo.org/ wcmsp5/ groups/ public/ ---asia/---ro-bangkok/ ---ilodhaka/documents/publication/wcms_2040 89.pdf

World Bank 2008. World Development Report 2008: Africulture for development (Washington, DC). Available at: http:// siteresources.worldbank.org/ INTWD R2008/Resources/WDR_00_book.pdf 